\title{
A Comparison of Toxic Product Yields Obtained From Five Laboratories Using the Steady State Tube Furnace (ISO TS 19700)
}

\author{
ANNA A. STEC ${ }^{\star 1}$, T.RICHARD HULL ${ }^{1}$, JENNY A. PURSER ${ }^{2}$, PER BLOMQVIST $^{3}$, and \\ KRZYSZTOF LEBEK ${ }^{4}$ \\ ${ }^{1}$ School of Forensic and Investigative Sciences, University of Central Lancashire, Preston, PR1 \\ 2HE \\ ${ }^{2}$ Hartford Environmental Research, Hertfordshire, UK (Formerly of BRE Ltd, UK) \\ ${ }^{3}$ SP Technical Research Institute of Sweden, P.O. Box 857, Boras S-501 15, Sweden \\ ${ }^{4}$ Centre for Materials Research and Innovation, University of Bolton, Deane Road, Bolton, BL3 \\ $5 A B, U K$
}

\begin{abstract}
The steady state tube furnace has been developed from BS 7990 into the first internationally recognized standard for assessment of fire gas toxicity, ISO TS 19700. The apparatus has been shown to reliably replicate different fire stages, and is capable of generating toxic product yields as a function of the equivalence ratio $\phi$. Work is reported from 5 laboratories currently using the steady state tube furnace where it has been used to assess the toxic product yields from a range of generic polymer materials, as a function of equivalence ratio. For the polymers tested, (LDPE, PP, PVC, Nylon, and PS) a high degree of reproducibility is observed across the range of ventilation conditions. In particular, the carbon monoxide yield, which is most susceptible to fire conditions shows consistent behaviour, which is independent of a particular laboratory.
\end{abstract}

KEYWORDS: toxicity, fire chemistry, hazard evaluation, steady state tube furnace, toxic product yields, reproducibility

\section{INTRODUCTION}

Fire hazard analysis requires assessment of threats to life from heat and smoke. Most fire deaths are attributed to inhalation of toxic gases and smoke. Fire effluents comprise narcotic (carbon monoxide (CO) and hydrogen cyanide $(\mathrm{HCN})$ ) and irritant (hydrogen chloride $(\mathrm{HCl})$, nitrogen oxides $\left(\mathrm{NO}, \mathrm{NO}_{2}\right)$ organoirritants etc.) gases and particulates. These can cause death directly (narcotics), or indirectly, by inhibiting breathing and preventing escape (gaseous and particulate irritants). The yields of almost all of these products are highly dependent on fire conditions, typically well-ventilated fires produce much lower yields of toxic products than well-developed, under-ventilated fires.

A long range goal of fire science is the ability to predict real-world fire performance from bench sale fire measurements. One concern is the toxicity of decomposition products. The recent publication of ISO 13571 [1] has driven the need for a reliable method for the quantification of toxic product yields for input into prediction of available safe egress time (ASET) from a building fire, requiring data on the yields and dispersion of the major toxic products.

Several bench scale toxicity protocols that quantify the toxicity of the smoke from burning materials have been developed, but only a few attempts have been made to correlate individual protocols with large scale results. The steady state tube furnace (ISO TS 19700) [2] (the Purser furnace) is one of the only methods to consistently replicate the toxic product yields of large scale fires on a bench scale. [3], [4], [5], [6] In contrast to most fire models which operate under conditions of fixed heat flux, this apparatus has been developed specifically to replicate the full range of fire conditions from oxidative pyrolysis to fully developed, underventilated flaming. This is achieved by driving the sample into a tube furnace at a fixed rate increasing the applied heat flux as it goes into the furnace. By controlling the fuel feed rate and air flow into a tubular furnace, steady burning can be achieved for different fuel/air ratios. This has been used for quantifying the toxic product yields of a number of polymers, [7] [8], [9], [10] and electric cables. [11], [12] The apparatus is shown in Fig. 1. 


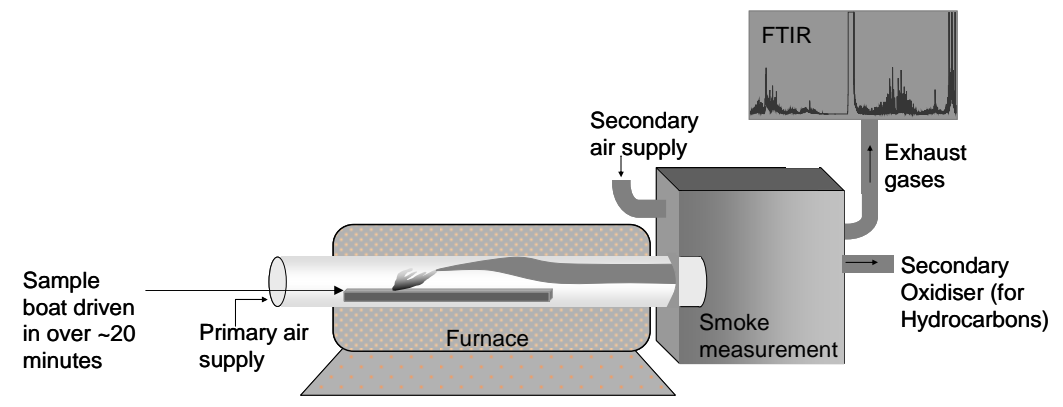

Fig. 1. Steady State Tube Furnace.

The apparatus typically consists of a tube furnace $(600-800 \mathrm{~mm}$ heating zone) and a quartz tube (1600$1700 \mathrm{~mm}$ ) which passes through the furnace and into a mixing and measurement chamber (27-34 litres capacity). The standard procedure uses a $20 \mathrm{~g}$ specimen uniformly placed in a test specimen boat $(800 \mathrm{~mm})$ to give a linear density of $25 \mathrm{mg} / \mathrm{mm}$. A drive mechanism pushes the specimen boat into the furnace tube at a rate of $40 \mathrm{~mm} / \mathrm{min}$ to give a fuel introduction rate of $1.00 \mathrm{~g} / \mathrm{min}$. A constant stream of primary air is provided at the furnace tube entry, and a secondary supply into the mixing chamber such that the total air flow is maintained at $501 / \mathrm{min}$. This provides a steady state mass charge concentration of $20 \mathrm{mg} / \mathrm{l}$ in the chamber. For materials that leave a residue or form a char, the residual mass is measured and product yields based on mass loss concentrations may be calculated. Gas samples are taken from the mixing chamber during the steady state period, and a light / photo cell system is used to determine smoke density across the mixing and measurement chamber if required.

Typical apparatus set-up parameters for common polymers are a primary air flow of $10 \mathrm{l} / \mathrm{min}$ for wellventilated conditions, reducing to $5 \mathrm{l} / \mathrm{min}$ or less for underventilated conditions. The specimen feed rate and air flows are adjusted to allow for the type or amount of material combusted in order to obtain the desired ventilation condition. The furnace temperature is also adjusted to compensate for cooling by the primary air flow, maintaining the nominal test temperature.

There are related considerations for assessing the accuracy of the data from the apparatus, namely repeatability for a number of identical test specimens, correlation of results to a particular fire stage, and reproducibility with different apparatuses. These have been reported elsewhere. [7], [13] This paper is focused on comparing toxic product yields obtained by different operators and different laboratories: BRE (Fire and Security) (UK), the University of Salford (UK), the University of Bolton (UK), Canterbury University (New Zealand), and SP Technical Research Institute of Sweden, and quantifying the reproducibility and to some extent, the repeatability of the ISO 19700 test method for characteristic fire types, mainly for well-ventilated and post-flashover tests. A summary of laboratories and materials included in this comparison is presented Table 1.

Table 1. Summary of Materials Tested in Different Laboratories.

\begin{tabular}{|l|c|c|c|c|c|c|c|}
\hline Material & \multicolumn{2}{|c|}{ BRE } & \multicolumn{2}{c|}{$\begin{array}{c}\text { University of } \\
\text { Salford }\end{array}$} & $\begin{array}{c}\text { University } \\
\text { of Bolton }\end{array}$ & SP & $\begin{array}{c}\text { Canterbury } \\
\text { University }\end{array}$ \\
\hline Operator: & $\mathbf{1}$ & $\mathbf{2}$ & $\mathbf{3}$ & $\mathbf{4}$ & $\mathbf{5}$ & $\mathbf{6}$ & $\mathbf{7}$ \\
\hline LDPE & $\sqrt{ }$ & $\sqrt{ }$ & & $\sqrt{ }$ & & & $\sqrt{ }$ \\
\hline PP & & & $\sqrt{ }$ & & & & \\
\hline PVC & $\sqrt{ }$ & $\sqrt{ }$ & & & $\sqrt{ }$ & & \\
\hline Nylon 6.6 & $\sqrt{ }$ & & & & $\sqrt{ }$ & $\sqrt{ }$ & \\
\hline Nylon 6 & & $\sqrt{ }$ & & & & & \\
\hline PS & $\sqrt{ }$ & $\sqrt{ }$ & $\sqrt{ }$ & & & & \\
\hline Reference & & {$[14]$} & {$[15]$} & {$[16]$} & {$[17]$} & {$[4]$} & {$[18]$} \\
\hline
\end{tabular}

The tests were carried out by 5 different laboratories at furnace temperatures between $650-850^{\circ} \mathrm{C}$. The operators were all graduate chemists, studying or having already obtained a $\mathrm{PhD}$. At BRE and the University of Salford, tests were carried out by two different operators at different times. This study has taken existing data obtained independently in the 5 laboratories, to look for broad agreement. It may be 
seen as a pre-cursor to the proposed formal study of interlaboratory reproducibility conducted in accordance with ISO TS 19700.[2] In each case the data were obtained as a function of ventilation condition, quantified by the equivalence ratio, $\phi$, (Eq. 1). This gives an indication of the degree of ventilation based on the chemical (stoichiometric) fuel/air ratio, and provides the best means of relating the fire condition to the toxic product yields.[19]

$$
\begin{aligned}
& \phi=\frac{\text { Actual Fuel / Air Ratio }}{\text { Stoichiometric Fuel / Air Ratio }} \\
& \phi=1 \text { "stoichiometric" combustion } \\
& \phi<<1 \text { well-ventilated fires (fuel lean flames) } \\
& \phi>1 \text { vitiated fires (fuel rich flames) } \\
& \phi>1 \text { vitiated fires (fuel rich flames) }
\end{aligned}
$$

The product yields are taken during the steady state period (of at least 5 minutes), which correspond to a particular equivalence ratio. Thus, a separate experiment is required for each value of $\phi$.

\section{MATERIALS}

All materials were used in pellet form. Low Density Polyethylene (LDPE) (operators 1, 2, and 4) was a commercial grade supplied by BICC General (Clearflex, Polimeri Europa). Polyproplyene (PP) and Polystyrene (PS) were commercial materials supplied by Northern Industrial Plastics. Nylon 6.6 was obtained as commercial fibre extrusion grade material from Invista (Operator 1) and from BASF Ultramid A3 containing 12.4\% nitrogen, 63.4\% carbon and 9.6\% hydrogen (Operator 6). Unplasticised or rigid Polyvinyl Chloride (PVC) was obtained as commercial grade material from Northern Industrial Plastics (Doeflex). Other materials LDPE, (operator 7) and Nylon 6, (operator 2) were unspecified commercial grade materials. For the purpose of this study, LDPE and PP, Nylon 6.6 and Nylon 6 are compared as though they were the same materials.

\section{GAS ANALYSIS}

The methods used to quantify the fire gases are presented in Table 2. Gas analyses in general were conducted using methodologies described in ISO 19701. [20] FTIR analysis was conducted using guidance from ISO 19702. [21]

Table 2. Summary of Gas Analysis Methods in Different Laboratories.

\begin{tabular}{|l|c|c|c|c|c|}
\hline Fire Gas & BRE & $\begin{array}{c}\text { University } \\
\text { of Salford }\end{array}$ & $\begin{array}{c}\text { University } \\
\text { of Bolton }\end{array}$ & SP & $\begin{array}{c}\text { Canterbury } \\
\text { University }\end{array}$ \\
\hline $\mathrm{CO}_{2}$ & NDIR & NDIR & NDIR & FTIR & FTIR \\
\hline $\mathrm{CO}$ & NDIR & NDIR & NDIR & FTIR & FTIR \\
\hline $\mathrm{HCN}$ & $\begin{array}{c}\text { Trapping solution/ } \\
\text { Spectrophotometry }\end{array}$ & N/A & N/A & FTIR & N/A \\
\hline $\mathrm{HCl}$ & $\begin{array}{c}\text { Trapping solution/ } \\
\text { ion chromatography }\end{array}$ & N/A & N/A & $\mathrm{b}$ & N/A \\
\hline NOx & Chemiluminescence $^{\text {Hydro- }}$ & N/A & N/A & FTIR & N/A \\
\hline carbon & Oxidising furnace $^{\text {a }}$ & N/A & N/A & N/A & N/A \\
\hline
\end{tabular}

a - The "unburnt" organic content was measured continuously by fully oxidising a sample of the effluent taken directly from the mixing chamber. The sample was passed through a high temperature furnace and the resulting total airborne carbon measured as $\mathrm{CO}_{2}$. The hydrocarbon content was calculated from the difference between fully oxidised $\mathrm{CO}_{2}$ and primary combustion $\mathrm{CO}_{2}+\mathrm{CO}$, and expressed in terms of $\mathrm{CH}_{2}$. $\mathrm{b}-\mathrm{HCl}$ is not relevant for the tests with Nylon-6.6 that SP provided data on. 


\section{FIRE CONDITIONS -TEMPERATURE AND VENTILATION}

All major combustion products were collected and analysed from the Purser Furnace apparatus. The burning conditions were adjusted to range from well-ventilated to under-ventilated for all tested materials and are together with temperatures presented in Table 3.

Most of the individual material/test conditions have direct comparisons with up to three other operators. In a few cases, only one operator data set is available, but it has been included to investigate the overall performance of the tube furnace apparatus.

Table 3. Fire Conditions for All Materials Studied.

\begin{tabular}{|c|c|c|c|c|c|c|c|c|}
\hline \multicolumn{2}{|c|}{ OPERATOR } & 1 & 2 & \multirow{2}{*}{$\frac{3}{\phi}$} & \multirow{2}{*}{$\begin{array}{c}4 \\
\phi\end{array}$} & \multirow{2}{*}{5} & \multirow{2}{*}{$\frac{6}{\phi}$} & \multirow{2}{*}{$\begin{array}{l}7 \\
\phi\end{array}$} \\
\hline Material & $\begin{array}{l}\text { Furnace } \\
\text { Temp } /{ }^{\circ} \mathrm{C}\end{array}$ & $\phi$ & $\phi$ & & & & & \\
\hline \multirow{3}{*}{$\begin{array}{l}\text { LDPE/ } \\
\text { PP }\end{array}$} & $650^{\circ} \mathrm{C}$ & \begin{tabular}{|ll}
0.58, & 0.82 \\
1.11, & 1.11 \\
1.23, & 1.49 \\
1.49 & \\
1.91 & \\
2.23 & \\
\end{tabular} & \begin{tabular}{|ll}
0.80, & 0.96 \\
0.96, & 1.49 \\
1.52, & 2.03 \\
2.32 & \\
2.52 & \\
3.00 & \\
\end{tabular} & & & & & $\begin{array}{l}0.70 \\
0.70 \\
0.70 \\
0.94 \\
0.94 \\
1.41\end{array}$ \\
\hline & $750^{\circ} \mathrm{C}$ & & & $\begin{array}{l}0.51 \\
0.74 \\
1.03 \\
1.54 \\
\end{array}$ & $\begin{array}{l}0.50 \\
0.70 \\
1.01 \\
1.49 \\
\end{array}$ & & & \\
\hline & $850^{\circ} \mathrm{C}$ & \begin{tabular}{|ll}
0.56, & 1.12 \\
1.13, & 1.13 \\
1.54, & 1.97 \\
2.55 & \\
2.78 & \\
\end{tabular} & $\begin{array}{l}1.70 \\
2.08\end{array}$ & & & & & \\
\hline \multirow{4}{*}{$\begin{array}{l}\text { Nylon } \\
6.6 \text { / } \\
\text { Nylon } 6\end{array}$} & $650^{\circ} \mathrm{C}$ & $\begin{array}{l}0.83 \\
1.20 \\
1.39 \\
1.49 \\
1.70 \\
2.06\end{array}$ & $\begin{array}{l}0.51 \\
0.81 \\
0.99 \\
1.50 \\
2.03 \\
2.49\end{array}$ & & & $\begin{array}{l}0.70 \\
1.00 \\
1.20 \\
1.40 \\
1.50 \\
1.85 \\
2.00\end{array}$ & $\begin{array}{l}0.55 \\
0.55 \\
0.83 \\
0.83 \\
1.15\end{array}$ & \\
\hline & $750^{\circ} \mathrm{C}$ & $\begin{array}{l}0.73 \\
1.03 \\
1.52 \\
2.10 \\
\end{array}$ & & & & & & \\
\hline & $825^{\circ} \mathrm{C}$ & & & & & & $\begin{array}{l}1.15 \\
2.04 \\
2.04 \\
2.04 \\
\end{array}$ & \\
\hline & $850^{\circ} \mathrm{C}$ & $\begin{array}{l}0.73 \\
1.03 \\
2.09\end{array}$ & $\begin{array}{l}1.51 \\
1.66 \\
2.03\end{array}$ & & & & & \\
\hline \multirow{3}{*}{ PS } & $650^{\circ} \mathrm{C}$ & $\begin{array}{l}0.55 \\
1.11 \\
1.71\end{array}$ & $\begin{array}{l}0.50 \\
0.80 \\
0.99 \\
1.49 \\
1.99 \\
\end{array}$ & & & & & \\
\hline & $750^{\circ} \mathrm{C}$ & $\begin{array}{l}0.58 \\
0.80 \\
1.14\end{array}$ & & $\begin{array}{l}0.47 \\
0.65 \\
0.94 \\
1.40\end{array}$ & & & & \\
\hline & $850^{\circ} \mathrm{C}$ & $\begin{array}{l}0.58 \\
0.80 \\
1.15 \\
1.75\end{array}$ & & & & & & \\
\hline
\end{tabular}




\begin{tabular}{|c|c|c|c|c|}
\hline \multirow{3}{*}{ PVC } & $650^{\circ} \mathrm{C}$ & $\begin{array}{l}0.58 \\
1.37\end{array}$ & $\begin{array}{l}0.40 \\
0.81 \\
1.01 \\
1.49 \\
1.99\end{array}$ & \\
\hline & $750^{\circ} \mathrm{C}$ & $\begin{array}{l}0.35 \\
0.58 \\
0.76 \\
1.13 \\
1.37\end{array}$ & & $\begin{array}{l}0.23 \\
0.33 \\
0.42 \\
0.70 \\
1.00\end{array}$ \\
\hline & $850^{\circ} \mathrm{C}$ & $\begin{array}{l}0.59 \\
1.39\end{array}$ & & \\
\hline
\end{tabular}

\section{PP AND LDPE}

Figure 2 presents results from operators 1, 2, 3, 4 and 7 for PP/LDPE. In common with many non-aromatic hydrocarbon polymers, they show very similar behaviour and for the purposes of this study have been compared together.

The theoretical yield ( $100 \%$ conversion of fuel carbon to $\mathrm{CO}_{2}$ ) for LDPE or PP is $3.14 \mathrm{~g} / \mathrm{g}$ under wellventilated conditions. It can be seen that almost all the fuel carbon is converted to $\mathrm{CO}_{2}$. The results in Fig.2 show the $\mathrm{CO}_{2}$ yield following almost linearly as the ventilation is decreased, while the $\mathrm{CO}$ yield increases with decrease in ventilation from $\phi=0.5$ to $\phi=1.5$ then starts to decrease slowly. The net effect on the $\mathrm{CO}_{2} / \mathrm{CO}$ ratio is a steady decrease until $\phi$ reaches 1.5 where it settles to a steady value. In contrast to $\mathrm{CO}$, the hydrocarbon yield, another product of incomplete combustion increases almost linearly as $\phi$ increases from $\phi=0.5$.

a)

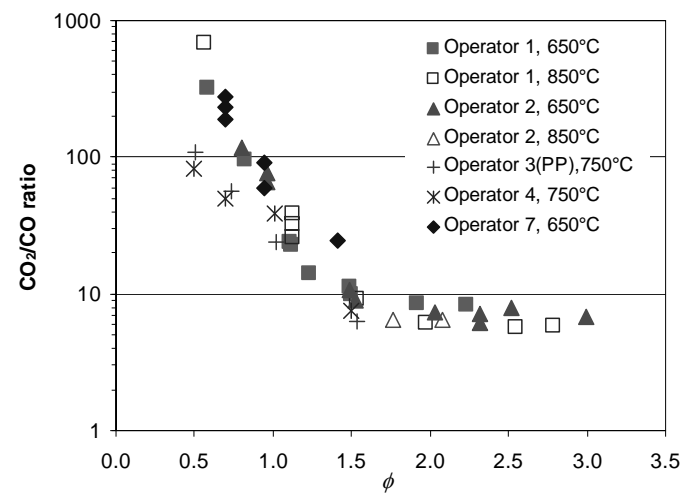

c)

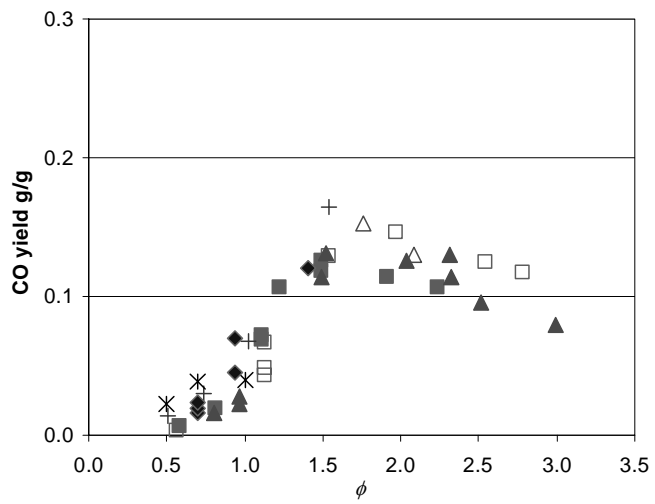

b)

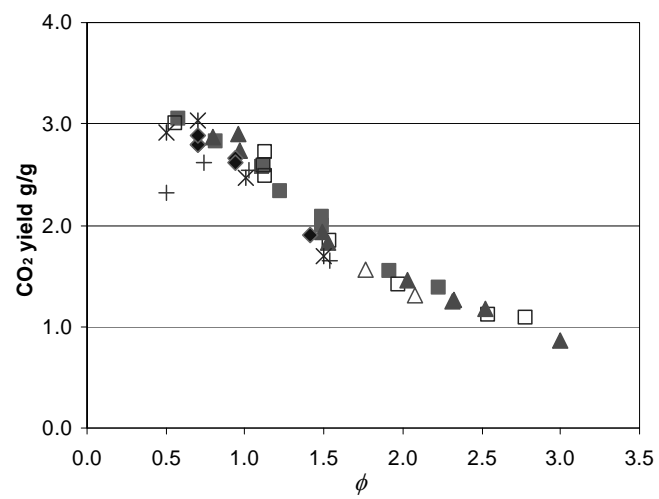

d)

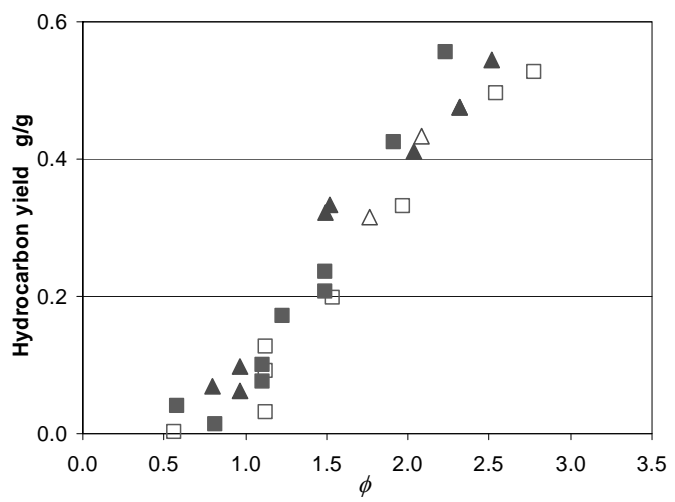

Fig. 2. Comparison of a) $\mathrm{CO}_{2} / \mathrm{CO}$ Ratio and Yields of b) $\mathrm{CO}_{2}$, c) $\mathrm{CO}$ and d) Hydrocarbon from LDPE and PP. 
Figure 2a shows the $\mathrm{CO}_{2} / \mathrm{CO}$ ratio plotted on a log scale expressed as a function of equivalence ratio. This shows a consistent and progressive decrease from $\phi=0.5$ to $\phi=1.5$, which then remains stable between $\phi=1.5$ and $\phi=3.0$ at $\mathrm{CO}_{2} / \mathrm{CO}$ ratio of around 7. Although there is a greater degree of scatter in the data under well-ventilated conditions, the data show very good agreement.

Figure $2 \mathrm{~b}$ shows the $\mathrm{CO}_{2}$ yield as a function of $\phi$, showing a steady and consistent decrease in $\mathrm{CO}_{2}$ with increase in $\phi$. Again there is very good agreement between laboratories.

Figure $2 \mathrm{c}$ shows the $\mathrm{CO}$ yield as a function of $\phi$. This shows a sharply upward trend from $\phi=0.5$ to $\phi=$ 1.5 , followed by a slight downward trend from $\phi=1.5$ to $\phi=3.0$. There is more scatter in the data, but given the overall lower concentrations and the well known sensitivity of $\mathrm{CO}$ yields to fire conditions, this is not surprising. It is interesting to note the consistency of the decrease of CO yield as the degree of vitiation increases.

Figure $2 \mathrm{~d}$ shows the hydrocarbon yield as a function of $\phi$. There is a consistent well correlated upward trend with $\phi$.

There is no obvious difference in the data obtained for polyethylene and propylene. The scatter observed for some parameters is to some extent attributable to differences in test temperature.

\section{NYLON 6.6 AND NYLON 6}

Figure 3 presents results from operators 1, 2, 5, and 6 for Nylon 6 and Nylon 6.6. Nylon 6 and Nylon 6.6 are chemically similar and were compared together. Although, the data set is incomplete, the yields of combustion products show good agreement between operators and laboratories, as a function of ventilation condition.

The results for Nylon 6 and Nylon 6.6 presented in Fig.3 show a similar trend to those for PP/LDPE, but with more scatter in the $\mathrm{CO}$ and $\mathrm{HCN}$ yield data giving a less pronounced steady $\mathrm{CO}_{2} / \mathrm{CO}$ yield as $\phi$ increases beyond 1.5. It is interesting to see that $\mathrm{HCN}$, a product of incomplete combustion, continues to increase with increasing $\phi$ while $\mathrm{CO}$ shows signs of leveling off above $\phi=0.5$. The $\mathrm{NO}_{\mathrm{x}}$ yields show greater scatter, but a sharp decrease with increase in $\phi$.

a)

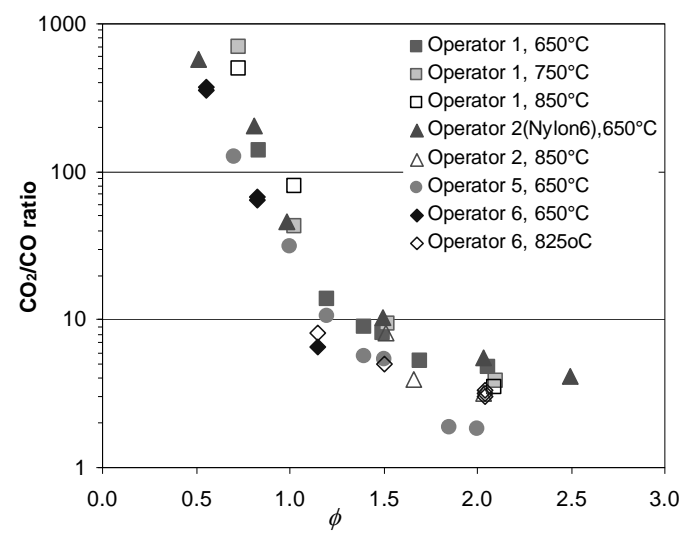

b)

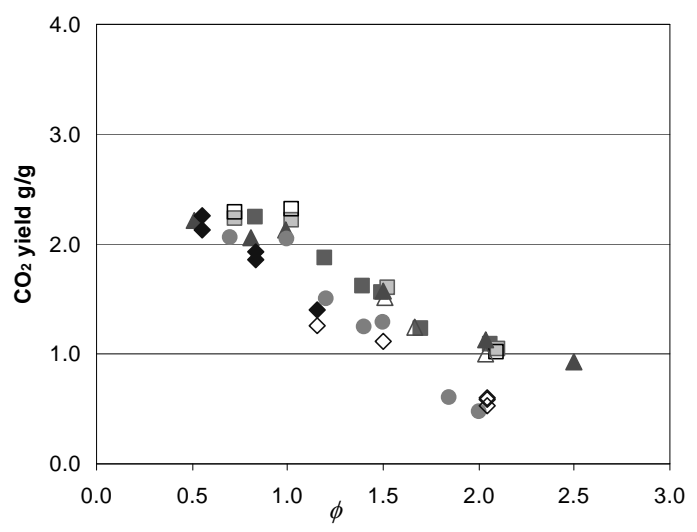


c)

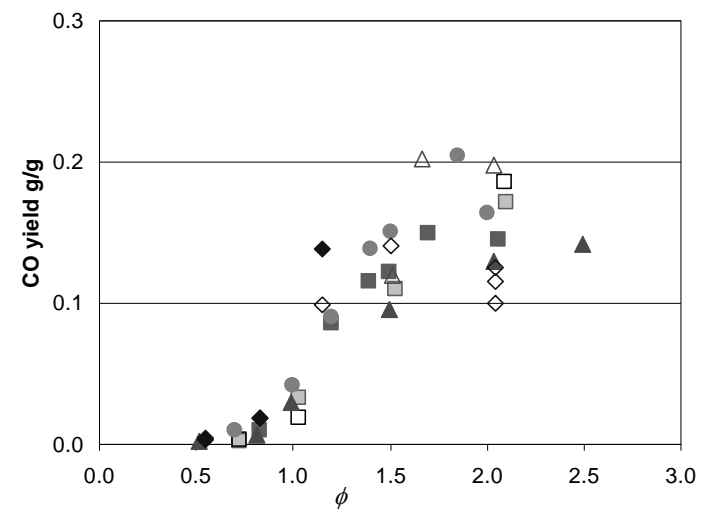

e)

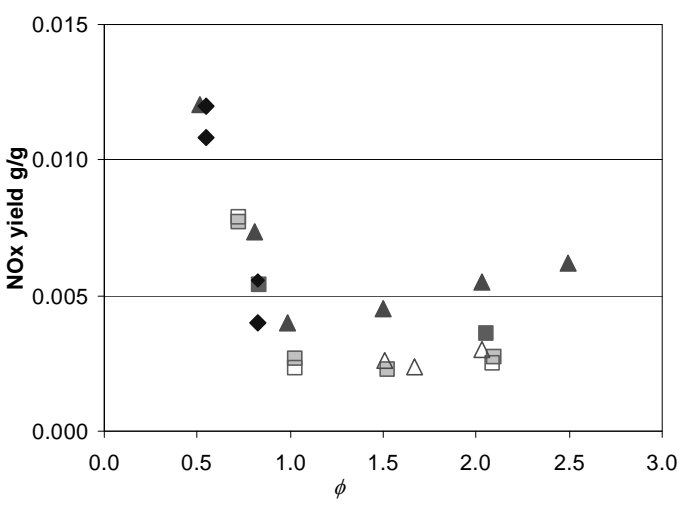

d)

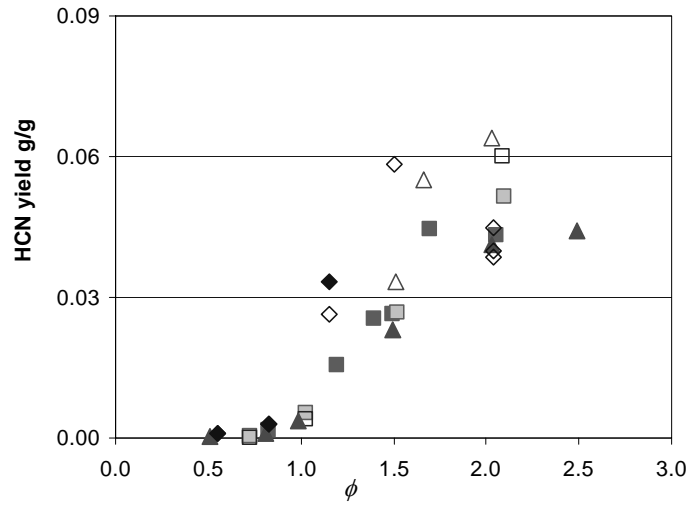

Fig. 3. Comparison of a) $\mathrm{CO}_{2} / \mathrm{CO}$ Ratio and Yields of b) $\mathrm{CO}_{2}$ and c) $\mathrm{CO}$ d) $\mathrm{HCN}$ e) $\mathrm{NO}_{\mathrm{x}}$ from Nylon 6.6 and Nylon 6.

Figure $3 \mathrm{a}$ presents the $\mathrm{CO}_{2} / \mathrm{CO}$ ratio expressed as a function of equivalence ratio, with $\mathrm{CO}_{2}$ yields presented in Fig. 3b, both showing a consistent and progressive decrease from $\phi=0.5$ to $\phi=1.5$. There is reasonable agreement between different laboratories and operators.

The yields for CO (Fig. 3c) and HCN (Fig. 3d) yields show an increase with increase in $\phi$. These products give broadly similar yields at different temperatures across the laboratories. However, for these operators, there is observed wider scatter as the fire becomes underventilated.

The $\mathrm{NO}_{\mathrm{x}}$ yields seem to have a greater sensitivity to different fire conditions, as shown in Fig. 3e. The $\mathrm{NO}_{\mathrm{x}}$ yields show a wide variation under conditions of low ventilation. However a downward trend from $\phi=0.5$ to $\phi=1.5$, and then a steady lower yields from $\phi=1.5$ to $\phi=3.0$ is observed. As expected, there is a higher sensitivity to furnace temperatures than for $\mathrm{CO}$ and $\mathrm{HCN}$ especially when $\phi>1.5$.

\section{POLYSTYRENE}

PS combustion products obtained from operators 1, 2, and 3 are presented in Fig. 4. The variation with $\phi$ shows consistent behaviour across the range of fire conditions for all products analysed. However, the greater temperature sensitivity of PS is particularly evident in the $\mathrm{CO}_{2} / \mathrm{CO}$ ratio. For well-ventilated conditions, where the higher $\mathrm{CO}$ yield is observed this corresponds to higher soot yield for aromatics and unsaturated fuels. Under fuel rich conditions, the lower $\mathrm{CO}$ yield are attributed to the greater thermal stability of the decomposition on products (styrene, and its dimer and trimer) which is largely responsible for greater $\mathrm{CO}$ formation under well-ventilated conditions. [15] 
a)

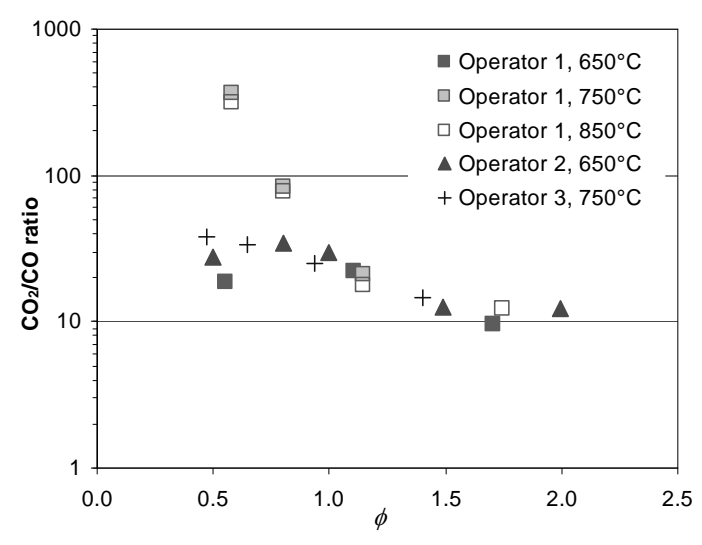

c)

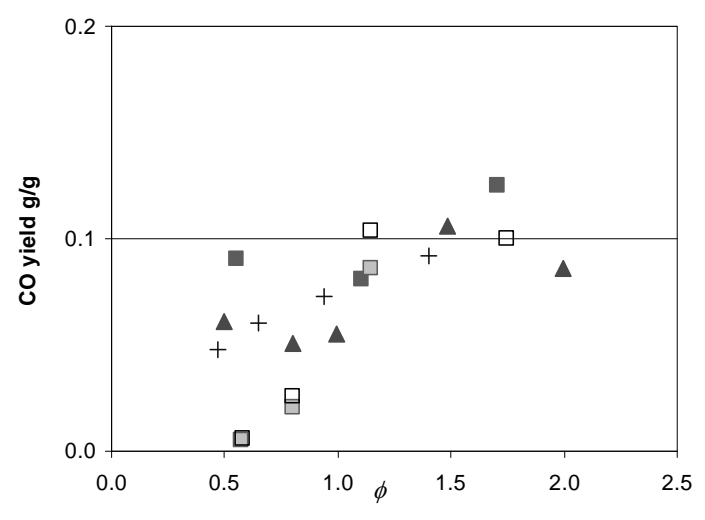

b)

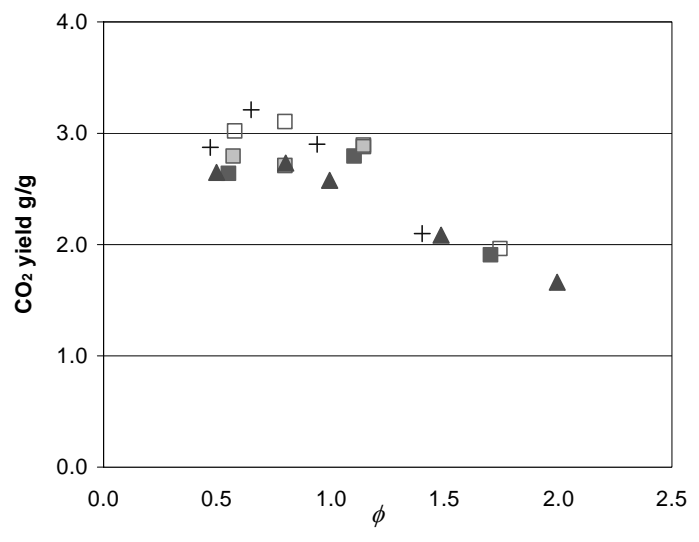

Fig. 4. Comparison of a) $\mathrm{CO}_{2} / \mathrm{CO}$ Ratio and Yields of b) $\mathrm{CO}_{2}$ and c) $\mathrm{CO}$ from Polystyrene.

A more gradual trend for PS, presented in Fig. $4 \mathrm{a}$, is observed for the $\mathrm{CO}_{2} / \mathrm{CO}$ ratio compared to PP/LDPE and Nylon 6.6/ Nylon 6 resulting from the greater thermal stability of the decomposition products forming more $\mathrm{CO}$ in well-ventilated conditions, but forming less $\mathrm{CO}$ in under-ventilated conditions. A good agreement is observed for different laboratories for data derived at the same temperature $\left(650^{\circ} \mathrm{C}\right)$.

Figure $4 \mathrm{~b}$ presents decreasing $\mathrm{CO}_{2}$ yields with the decrease of ventilation conditions.

The yields for CO (Fig. 4c), on the expanded y axis, show a steady increase with increase in $\phi$. These data show consistency at different temperatures and ventilation conditions and again, a sensitivity to temperature is observed for this material.

\section{PVC}

Figure 5 shows the combustion product yields for unplasticised PVC. The theoretical yield of $\mathrm{CO}_{2}$ from unplasticised $\mathrm{PVC}$ is $1.4 \mathrm{~g} / \mathrm{g}$, and complete conversion of fuel carbon to $\mathrm{CO}_{2}$ is approached at a furnace temperature of $850^{\circ} \mathrm{C}$, when the $\mathrm{CO}$ yield also falls. This implies that the flame quenching effect of $\mathrm{HCl}$, which inhibits the conversion of $\mathrm{CO}$ to $\mathrm{CO}_{2}$, the major heat release step of hydrocarbon combustion, is less effective at higher temperatures. The theoretical yield of $\mathrm{HCl}$ is $0.585 \mathrm{~g} / \mathrm{g}$ and it can be seen that most of the chlorine is released as $\mathrm{HCl}$. As has been reported elsewhere, [22] $\mathrm{HCl}$ inhibits the conversion of $\mathrm{CO}$ to $\mathrm{CO}_{2}$, giving much higher $\mathrm{CO}$ yields under well-ventilated conditions. However, there were differences in the analysis of the products in the experiments carried out by operator 5, who quantified the hydrocarbons by secondary oxidation of unfiltered fire effluent which would include soot (operators 1 and 2 filtered the fire effluent prior to secondary oxidation recording total soot yields separately); the small quantities of 
carbon monoxide measured in the secondary oxidiser effluent were not quantified; and the $\mathrm{HCl}$ and soot yields were not recorded.

The influence of ventilation conditions and furnace temperature on the $\mathrm{CO}_{2} / \mathrm{CO}$ ratio for $\mathrm{PVC}$ is shown in Fig. 5a. The trend is decreasing slightly with increase in $\phi$. Good agreement between different laboratories is observed for the same furnace temperature.

Figure $5 \mathrm{~b}$ presents $\mathrm{CO}_{2}$ yields as a function of equivalence ratio. Similarly to the $\mathrm{CO}_{2} / \mathrm{CO}$ ratio, $\mathrm{CO}_{2}$ yields decrease with increase in the ventilation conditions. There is very good agreement between different laboratories.

The $\mathrm{CO}$ yields in the steady state tube furnace, presented in Fig. $5 \mathrm{c}$, are almost constant with increase in $\phi$, and are dependent on furnace temperature.

Rigid, or unplasticised, PVC shows very high levels of toxicity predicted from the $\mathrm{HCl}$ in the fire effluent, which dominates the overall prediction of its fire toxicity. The most toxicologically significant species is hydrogen chloride $(\mathrm{HCl})$, whose yield is almost independent of fire condition, or apparatus (Fig. 5d). There is very good correlation of the results between different laboratories, and the yield for this toxic product is independent on furnace temperature.

The results for PVC hydrocarbon yields are presented in Fig. 5e. This shows a degree of scatter which has been interpreted elsewhere [10] as a diminution of the flame inhibiting effect of $\mathrm{HCl}$ with increases in temperature, though the effect on hydrocarbon yields is different to that on $\mathrm{CO}$ yields. This suggests that $\mathrm{HCl}$ only inhibits the conversion of $\mathrm{CO}$ to $\mathrm{CO}_{2}$ (presumably by removing $\mathrm{OH}$. radicals responsible for the reaction), but not the conversion of hydrocarbons to $\mathrm{CO}$, which is driven by oxygen depletion. There is fairly very good agreement between different laboratories obtained for different combustion product yields presented.

a)

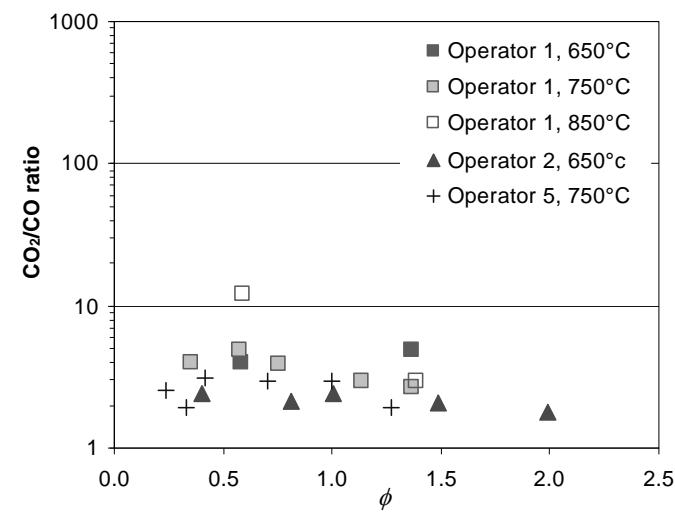

c)

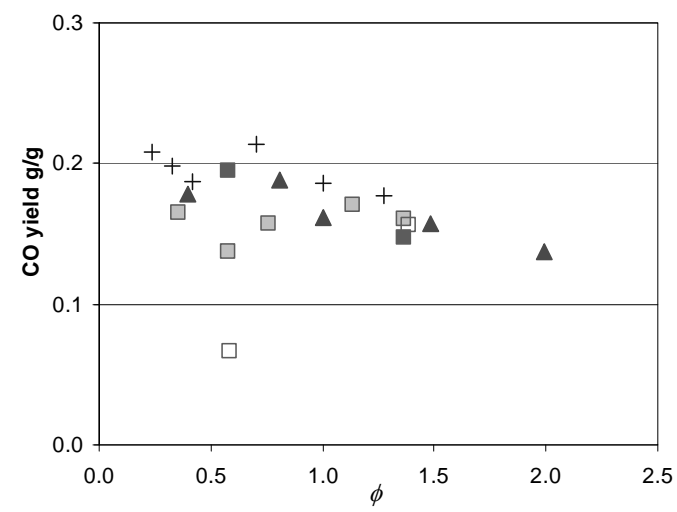

b)

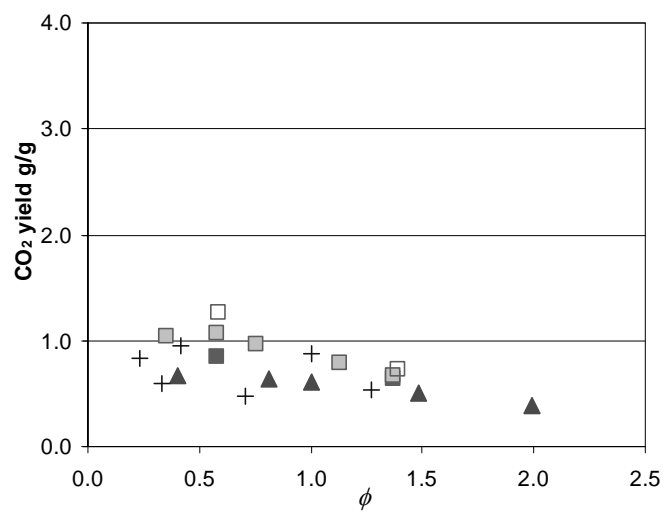

d)

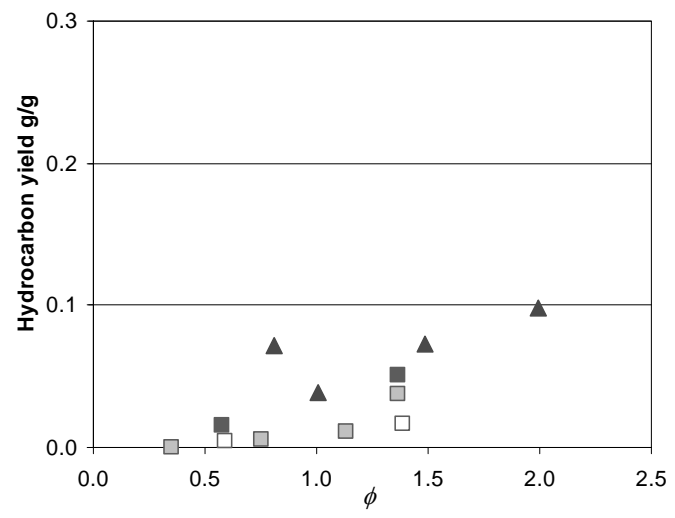


e)

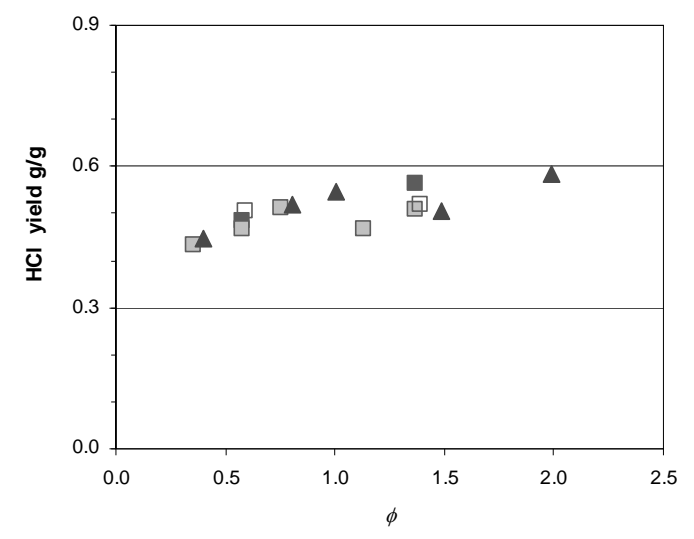

Fig. 5. Comparison of a) $\mathrm{CO}_{2} / \mathrm{CO}$ Ratio and Yields of b) $\mathrm{CO}_{2}$ and c) $\mathrm{CO}$ d) Hydrocarbon e) $\mathrm{HCl}$ from PVC.

\section{INFLUENCE OF TEMPERATURE}

The data presented were not collected for the purpose of an interlaboratory reproducibility exercise. Many were collected at different furnace temperatures. In order to investigate the influence of furnace temperature on the $\mathrm{CO}$ yield in well and under-ventilated conditions the data have been plotted in Fig. 6 . It shows the $\mathrm{CO}$ yield data obtained by a single operator/apparatus (1) for the four materials at three temperatures and at both low $\phi$ (0.6 to 0.8 and high $\phi(1.4$ to 2.0$)$ values. The data at $750^{\circ} \mathrm{C}$ are missing either because of a $\mathrm{CO}$ analyser malfunction or lack of experiments conducted at that temperature.

a)

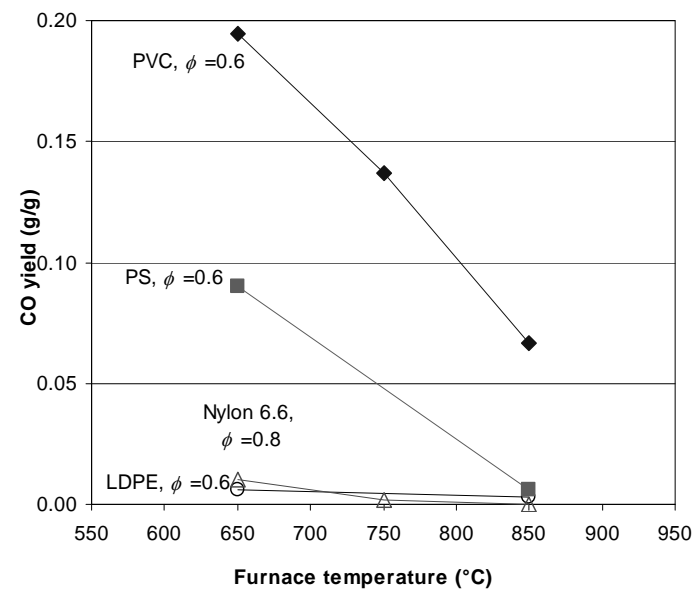

b)

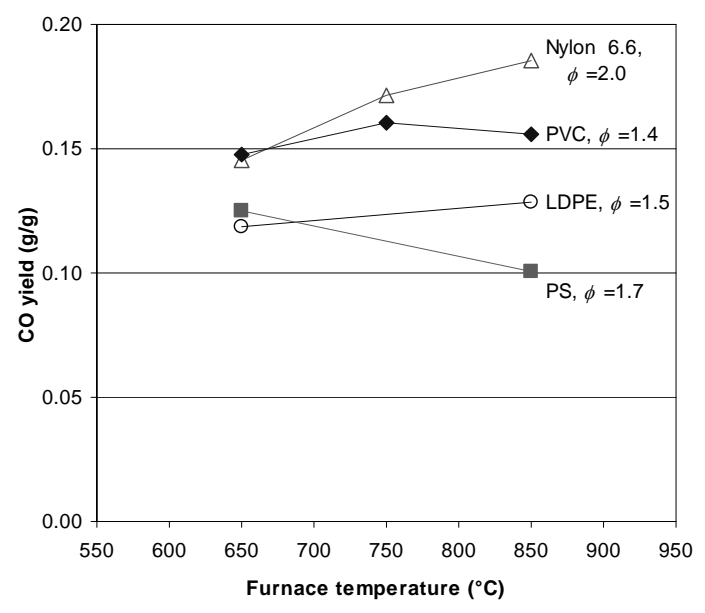

Fig. 6. Influence of Temperature on CO Yields at a) $\phi<1.0$, and b) $\phi>1.0$ for LDPE, Nylon 6.6, PS and PVC.

Figure 6a clearly shows that, at low $\phi$, temperature had a small influence on both LDPE and Nylon 6.6, but at high $\phi$, it had a dramatic effect on PS and PVC resulting in much decreased yields at the higher temperatures. On the other hand, Fig. $6 \mathrm{~b}$ shows an opposite trend, such that three of the materials (LDPE, Nylon 6.6 and PVC) experienced an increase in CO yield, albeit only marginal, and the fourth material (PS) had a reduced CO yield at the higher temperature. Since the flame temperature, or ambient temperature around the burning sample, will differ significantly from the furnace temperature, data were compared from experiments carried out at different furnace temperatures with two notable exceptions $\left(\mathrm{PVC}\right.$ at $850^{\circ} \mathrm{C}$ and 
PS at $750^{\circ} \mathrm{C}$ and $850^{\circ} \mathrm{C}$ both under well-ventilated conditions). This did not seem to make any significant difference.

\section{CONCLUSIONS}

Similarly to the behaviour of real fires, the yields of toxic gases in the steady state tube furnace are highly dependent on the decomposition conditions, in particular the fuel/air equivalence ratio, or the $\mathrm{CO}_{2} / \mathrm{CO}$ ratio, which provides a measure of combustion efficiency. The exceptions are PVC and fire retarded polymers where halogens increase the $\mathrm{CO}$ yield under well-ventilated conditions, reducing the heat release rate. Indeed ISO 19706 notes that $\mathrm{CO}_{2} / \mathrm{CO}$ ratio is only indicative of fire conditions for materials which do not contain halogens. This effect is clearly visible in the data from the PVC experiments.

The combustion product yields for all materials show reasonably good inter-operator agreement for $\mathrm{CO}$, $\mathrm{CO}_{2}, \mathrm{HCN}, \mathrm{HCl}, \mathrm{NO}_{\mathrm{x}}$, and hydrocarbons. Where there are apparent large discrepancies, it is attributable to either the influence of temperature, or true operator/laboratory differences. It can be concluded that the steady state tube furnace measurements can be made independent of laboratory or operator. In many cases (at least for thermoplastics) there is also a significant degree of independence from furnace temperature. Thus, the toxic product yields from different combustion scenarios, for use as a bench-scale quantification of toxic product yields, can be used to characterise the burning behaviour of materials under controlled and well-defined laboratory conditions. Since each test run represents the burning behaviour for a particular fire stage, the results are more generally applicable than those of a single large scale test, where the different fire stages can be difficult to separate in smoke gas analysis.

Repeatability and reproducibility obtained by different operators and laboratories shows that there is a low sensitivity to differences in operator or individual laboratory setups. Studies such as these are relatively inexpensive compared to large-scale tests, taking less time and having higher reproducibility.

\section{REFERENCES}

[1] ISO 13571:2007 Life-threatening components of fire-Guidelines for the estimation of time available for escape using fire data, 2007.

[2] ISO TS 19700:2007 Controlled equivalence ratio method for the determination of hazardous components of fire effluents, 2007.

[3] Stec, A.A., Hull, T.R., Purser, J.A., and Purser, D.A., Comparison of Toxic Product Yields from Bench-Scale to ISO Room, Fire Safety Journal, March 2008 (in press).

[4] Blomqvist, P., Hertzberg, T., and Tuovinen H., A small-scale controlled equivalence ratio tube furnace method - experience of the method and the link to large scale fires, Proceedings of the 10th International Fire Science and Engineering Conference (Interflam), Edinburgh, 2007.

[5] Hull, T.R., Lebek, K., Stec, A.A., Paul K.T., and Price, D., Bench-Scale Assessment of Fire Toxicity, in Advances in the Flame Retardancy of Polymeric Materials: Current perspectives presented at FRPM'05 Ed. B Schartel, Berlin, 2007 (in press).

[6] Hull, T.R., Lebek, K., Paul, K.T., Pezzani, M., and Messa, S., Comparison of cable fire toxicity data from steady state and static tube furnaces with large scale test, Fire Safety Journal, 2008, 43, Issue 2, pp. 140-150. doi:10.1016/j.firesaf.2007.06.004

[7] Stec, A.A., Hull, T.R., Lebek, K., Purser, J.A., Purser, D.A., The effect of ventilation condition on the toxic product yields from burning polymers, Fire and Materials, 32, January/February 2008, Issue 1, pp. 49-60. doi:10.1002/fam.955

[8] Hull, T.R., Quinn, R.E., Areri, I.G., and Purser, D.A., Combustion toxicity of fire retarded EVA, Polymer Degradation and Stability, 2002, 77, pp. 235-242. doi:10.1016/S0141-3910(02)00039-3

[9] Lebek, K., Hull, T.R., and Price, D., Products of burning rigid PVC burning under different fire conditions, Fire and Polymers: Materials and Concepts for Hazard Prevention, ACS Symposium Series No.922, Oxford University Press, 2005, pp. 334-347. 
[10] Hull, T.R., Stec, A.A., Lebek, K., and Price, D., Factors affecting the combustion toxicity of polymeric materials, Polymer Degradation and Stability, 92, 2007, pp. 2239-2246. doi:10.1016/j.polymdegradstab.2007.03.032

[11] Hull, T.R., Wills, C.L., Lebek, K., Paul, K.T., and Price, D., Methodology for small-scale toxic hazard assessment of burning cables, Fire and Polymers: Materials and Concepts for Hazard Prevention, ACS Symposium Series No.922, Oxford University Press, 2005, pp. 348-353.

[12] Robinson, J.E., Hull, T.R., Lebek, K., Acidity, toxicity and European cable regulation, Transactions of the International Wire and Cable Symposium (Trans-IWCS) Boston, 2007 (In Press).

[13] Stec, A.A., Hull, T.R., and Lebek, K., Characterisation of the steady state tube furnace (ISO TS 19700) for fire toxicity assessment, Polymer Degradation and Stability, (Submitted Sept 2007).

[14] Purser, J.A., Private Communication, 2007.

[15] Hull, T.R., Carman, J.M., and Purser, D.A., Prediction of CO evolution from small-scale polymer fires, Polymer International, 49, 2001, pp. 1259-1265. doi:10.1002/10970126(200010)49:10<1259::AID-PI573>3.0.CO;2-D

[16] Carman, J.M., Purser, D.A., Hull, T.R., Price, D., Milnes, G.J., Experimental parameters effecting the performance of the Purser furnace - a laboratory scale experiment for a range of controlled real fire conditions, Polymer International, 49, 2000, pp. 1256-1258. doi:10.1002/10970126(200010)49:10<1256::AID-PI500>3.0.CO;2-W

[17] Hull, T.R., Lebek, K., Stec, A.A., Paul, K.T., and Price, D., Advances in the Flame Retardancy of Polymeric Materials: Current perspectives presented at FRPM'05, Ed. B Schartel, Berlin, 2007 (in press).

[18] Anderson, P., Private communication, University of Canterbury, New Zealand, 2008.

[19] ISO 19703:2005 Generation and analysis of toxic gases in fire-Calculation of species yields, equivalence ratios and combustion efficiency in experimental fires, 2005.

[20] ISO 19701:2005 Methods for sampling and analysis of fire effluents, 2005

[21] ISO 19702:2006 Toxicity testing of fire effluents -Guidance for analysis of gases and vapours in fire effluents using FTIR gas analysis, 2006

[22] Hull, T.R., Stec, A.A., Paul, K.T., Hydrogen chloride in Fires, Proceedings of the 8th International Symposium on Fire Safety Science (in press, April 2008). 